\title{
Enzymatic Markers of Pulmonary Inflammation in Tracheal Wash Fluid in Racehorses: Alkaline Phosphatase and Lactate Dehydrogenase
}

\author{
Cihan Kumaş ${ }^{1}$, Alper Mete' ${ }^{1}$ Şeref İnal' ${ }^{2}$ \& Mehmet Maden ${ }^{3}$
}

\begin{abstract}
Background: Diagnosis of the lower airway diseases (LAD) in horses relies on clinical signs, endoscopic examination and cytologic evaluation of lower respiratory tract flushing fluids as well. Specific enzyme activities in respiratory tract fluids of horses could be used as useful indicators in lower airway disorders. The main goal of the study was to evaluate the diagnostic usefulness of alkaline phosphatase (ALP) and lactate dehydrogenase (LDH) enzyme activites in tracheal wash (TW) fluids of horses with lower respiratory tract inflammation and/or damage and also in distinguishing of non-septic and septic inflammation in racehorses with LAD.

Materials, Methods \& Results: A cross-sectional study was conducted in racehorses. TW fluid samples were obtained from 83 racehorses ( 71 with lower airway diseases and 12 healthy controls) for the study. The One-Way ANOVA Test was used for the significance analysis of the differences between the groups in showing the normal distribution of blood serum ALP and LDH properties. Kruskal Wallis H Test and Tamhane T2 test were used for the significance analysis of the differences between the groups of tracheal ALP and LDH properties, which were not normally distributed. The sampled horses were classified into 3 groups as healthy control, non septic neutrophilic inflammation (NS-LAD) and septic neutrophilic inflammation (S-LAD) according to the tracheal mucus scores determined during endoscopic examination, clinical signs, cytologic and bacteriologic examination of collected TW samples. According to cytology results normal neutrophil levels $(<20 \%)$ were determined in the healthy control group $(14.5 \%)$. However, increased neutrophil levels $(\geq 20 \%$ and $\geq 80 \%)$ were encountered in the NS-LAD $(61.4 \%)$ and S-LAD $(24.1 \%)$ groups respectively. Also, the signs of degenerative changes and presence of intracellular bacteria in the neutrophil cells in the S-LAD group were observed. Bacteriologic analysis of the samples revealed Streptococcus equi subsp. zooepidemicus was the most prevalent agent (85.6\%) followed by Escherichia coli (4.8\%), Staphylococcus aureus $(4.8 \%)$ and Klebsiella pneumoniae (4.8\%). ALP and LDH enzyme activities of TW fluid were found to be significantly higher in racehorses with LAD compared with healthy controls $(P<0.01)$. On the other hand, a significant difference was also determined for LDH levels between NS-LAD and S-LAD cases determining with cytological and bacteriological examination $(P<0.01)$. Serum ALP and LDH levels of racehorses were revealed no significant difference between each study groups.

Discussion: Respiratory system diseases have been known as one of the main causes of training disruption and interruption of racing events in racehorses. Specifically, LAD is the most frequently diagnosed disorder in racehorses with poor performance. In the present study established for determining the usefulness of ALP and LDH enzyme levels in the TW samples of horses with lower respiratory tract inflammatory disorders. It was concluded that ALP and LDH enzyme activities of TW fluid could be considered as indicators of pulmonary inflammation and/or damage and LDH enzyme activity is thought to be useful in distinguishing neutrophilic non-septic and septic pulmonary inflammation in racehorses with LAD. On the other hand, data obtained from the study indicated that TW fluid ALP activity was not enough statistically to differenatiate horses with non-septic and septic lower airway inflammation.
\end{abstract}

Keywords: ALP, LDH, tracheal wash fluid, lower airway disease, racehorse.

DOI: $10.22456 / 1679-9216.99755$

${ }^{1}$ Veliefendi Racecourse Horse Hospital, Jockey Club of Turkey, İstanbul, Turkey. ${ }^{2}$ Department of Animal Breeding \& ${ }^{3}$ Department of Internal Medicine, Faculty of Veterinary Medicine, University of Selcuk, Konya, Turkey. CORRESPONDENCE: M. Maden [mmaden@ selcuk.edu.tr]. Department of Internal Medicine, Faculty of of Veterinary Medicine, University of Selcuk. 42003 Konya, Turkey. 


\section{INTRODUCTION}

Inflammatory airway diseases (IAD) have been identified as one of the main causes of lacking training and racing interruption in thoroughbred racehorses [4]. Diagnosis of the lower airway diseases (LAD) mainly relies on endoscopic examination, which is an important tool for both clinical use and scientific investigation of lower airways of racehorses [10]. Evaluation of tracheal wash (TW) and/or bronchoalveolar lavage fluid (BALF) cytologically and microbiologically in suspected cases are also performed. Relative proportion $(\%)$ of inflammatory cells are determined in respiratory tract fluid cytology.

Cytoplasmic enzymes such as alkaline phosphatase (ALP), lactate dehydrogenase (LDH) are known as indicators of cell damage or death $[5,15]$. Serum ALP activity is normally presented in bone, intestinal mucosa, renal tubule cells and biliary epithelium in horses [22,26]. Serum LDH activity was more highly concentrated in skeletal muscle, cardiac muscle, kidney and liver [25]. ALP and LDH increase were also induced by elevated leucocytes particularly neutrophil activity in different pathological conditions including bacterial, viral infections and malignancy in humans $[6,9,17]$. ALP activity was found to be higher in asymptomatic lower airway inflammation compared with healthy controls in horses [27]. In dogs ALP and LDH activities significantly increased in bronchopneumonia group [19].

The present study aimed to evaluate the usefulness as indicators of lower respiratory tract inflammation of ALP and LDH enzyme activities in TW samples and also in distinguishing of non-septic and septic inflammation in racehorses with LAD.

\section{MATERIALS AND METHODS}

\section{Animals and sampling}

Cross-sectional study was conducted on animals for the study. A total of 83 tracheal wash samples were collected from 80 thoroughbred $(96.4 \%)$ and 3 Arabian (3.6\%) racehorses for the study. Mean ages of the sampled horses were 2.8 years old and ranged between 2-5 years old. All of the horses sampled were resided in closed barns located in Veliefendi Racetrack/ Istanbul. Sample collections were performed according to the previous study $[12,21]$. Briefly, a sterile polyethylene tube (Jorgen Kruuse) ${ }^{1}$ was introduced through the endoscopy biopsy channel to collect the secretion from the distal end of the trachea that was adjacent to the carina. To all horses $40 \mathrm{~mL}$ sterile $0.9 \%$ sodium chloride solution was instilled and approximately $60 \%$ instilled solution was aspirated back to a $60 \mathrm{~mL}$ sterile syringe. Maximum precautions were taken to reduce the risk of upper airway contamination. After collecting the samples, they were transfered immediately to a 10 $\mathrm{mL}$ plane tube ${ }^{2}$ for bacteriology, measurement of $\mathrm{LDH}$ and ALP concentration and $4.5 \mathrm{~mL}$ ethylenediaminetetraacetic acid (EDTA) tube (Diasera) ${ }^{2}$ for cytologic examination.

\section{Clinical assessment}

Before collecting samples, all horses were clinically examined and recorded for the presence or absence of high rectal temperature $\left(38.6^{\circ} \mathrm{C} \leq\right)$, nasal discharge, coughing at rest and pharyngeal lymphoid hyperplasia. Tracheal mucus accumulation was also determined and graded as numeric score between 0 (none, clean, singular mucus) and 5 (extreme profuse amounts of mucus) during endoscopic examination according to the previous study [10]. TW mucus score more than one $(>1)$ was also considered as a positive pathological finding of the lower respiratory tract according to a previous study [18].

Cytology

Slide preparations were made by centrifugation of the TW samples at $400 \mathrm{~g}$ for $5 \mathrm{~min}$. The slides were prepared from the sediment of the centrifuged TW samples as described before [7]. The air-dried slides were stained with May Grünwald quick stain $(\mathrm{GBL})^{6}$ that were used according to the manufacturer's instructions. The slides were examined under $100 \mathrm{X}$ magnification microscope and relative proportions (\%) of the neutrophils, macrophages, lymphocytes, eosinophils and mast cells were determined by couting 200 cells [4]. The slides were carefully examined for morphological changes in neutrophils such as degeneration of cells, karyolysis, cytoplasmic vacuolation and presence of intracytoplasmic bacteria as well. The cytology results were classified as normal cytologic pattern (neutrophils $<20 \%$ ), neutrophilic non-septic inflammation (20\% $\leq$ neutrophils) and neutrophilic septic inflammation $(20 \% \leq$ neutrophils, with degenerative changes and presence of intracellular bacteria) as described in previous review articles [4,20]. 
Bacteriology

Bacteriological examinations of the TW samples were carried out as described before [16,23]. Bacterial identifications were carried out by using BBL crystal ID gram positive and enteric/non fermenter ID systems (BD) ${ }^{3}$. Lancefield grouping of streptococci isolates were also performed with commercially avaible latex agglutination test kit (Oxoid) ${ }^{4}$ according to the manufacturer's recommendations. Briefly, the samples were inoculated in 5\% sheep blood agar and mac conkey agar in both aerobic and microaerophilic $\left(5 \% \mathrm{CO}_{2}\right)$ conditions. The agars were incubated 24-48 $\mathrm{h}$ for bacterial growth. After the incubation period, the cultures were examined for the growth of bacterial colonies which were considered as pathogenic for horses according to the previous studies $[3,13]$.

\section{Determination of enzyme activities in serum and TW fluid samples}

TW fluid samples collected in $10 \mathrm{~mL}$ plane tubes were used for enzyme activity analysis. The samples were centrifuged at $400 \mathrm{x} g$ for $5 \mathrm{~min}$. Blood samples were also collected from jugular vein of the horses and were spun at $2500 \mathrm{x} g$ for $10 \mathrm{~min}$. The supernatants of the TW fluid and serum samples were seperated and handled immediately after collection for measurement of ALP and LDH levels in automated biochemistry analyser (Siemens) $)^{5}$ [22]. The sediments of the centrifuged TW samples were then used for cytological examination.

\section{Statistical analysis}

Normality tests were applied to all data in order to determine the statistical analysis methods to be applied to the data of the investigated properties. The One-Way ANOVA Test was used for the significance analysis of the differences between the groups in showing the normal distribution of blood serum ALP and LDH properties. Kruskal Wallis H Test and Tamhane T2 test were used for the significance analysis of the differences between the groups of TW sample ALP and LDH properties, which were not normally distributed [24].

\section{RESULTS}

Based on clinical, endoscopic, cytological and bacteriological findings, $14.5 \%(\mathrm{n}=12), 61.4 \%(\mathrm{n}=$ $51)$ and $24.1 \%(n=20)$ of the 83 horses sampled, were classified as healthy control, neutrophilic non-septic inflammation (NS-LAD) and neutrophilic septic inflammation (S-LAD) groups respectively.

Cytology results revealed $12(14.5 \%)$ of the 83 racehorses had normal neutrophil levels $(<20 \%)$ in the healthy control group; fifty-one $(61.4 \%)$ horses had increased neutrophil levels $(\geq 20 \%)$ in the NS-LAD group; and on the other hand, twenty $(24.1 \%)$ horses had increased levels of neutrophils $(\geq 80 \%)$ also with signs of degenerative changes and presence of intracellular bacteria in the neutrophil cells, which were classified as S-LAD (Table 1). The statistical analysis revealed significant differences in the proportion of neutrophils, lymphocytes and macrophages between healthy control, NS-LAD and S-LAD groups $(P<0.01)$.

According to the bacteriological examinations Streptococcus equi subsp. zooepidemicus was determined to be the dominant etiologic agent isolated from $18(85.6 \%)$ horses with septic inflammation. Escherichia coli, Klebsiella pneumoniae and Staphylococcus aureus was also isolated from each one (4.8\%) horse with septic neutrophilic inflammation.

While statistically significant difference $(P<$ 0.01 ) was found between all group's mean ALP and LDH enzyme activities except as the difference was statistically insignificant between NS-LAD and S-LAD groups for ALP levels in TW fluid (Table 2), no statistically significant difference was found in blood serum enzyme activities between groups (Table 3).

Table 1. Mean \pm SD differential cell counts of TW samples obtained from healthy control, NS-LAD and S-LAD group.

\begin{tabular}{ccccc}
\hline Parameter & $\begin{array}{c}\text { Healthy control } \\
(\mathrm{n}=12)\end{array}$ & $\begin{array}{c}\text { NS-LAD } \\
(\mathrm{n}=51)\end{array}$ & $\begin{array}{c}\text { S-LAD } \\
(\mathrm{n}=20)\end{array}$ & $\begin{array}{c}\text { KW } \\
P\end{array}$ \\
\hline Neutrophils $(\%)$ & $10.58 \pm 2.94 \mathrm{c}$ & $51.35 \pm 22.73 \mathrm{~b}$ & $90.65 \pm 7.20 \mathrm{a}$ & 0.000 \\
Lymphocytes $(\%)$ & $3.25 \pm 3.17 \mathrm{~b}$ & $4.86 \pm 4.83 \mathrm{~b}$ & $1.18 \pm 1.82 \mathrm{a}$ & 0.000 \\
Macrophages (\%) & $55.25 \pm 21.46 \mathrm{a}$ & $37.06 \pm 21.91 \mathrm{a}$ & $5.36 \pm 5.90 \mathrm{~b}$ & 0.000 \\
Eosinophils (\%) & $0.00 \pm 0.00$ & $1.41 \pm 5.03$ & $0.30 \pm 0.66$ & 0.178 \\
Mast cells (\%) & 0 & 0 & 0 & 1.000 \\
\hline
\end{tabular}

NS-LAD $=$ Non Septic Lower Airway Disease; $S-L A D=$ Septic Lower Airway Disease; $K W=$ Kruskal Wallis H Test; a,b,c= Means that have the same letter on the same row are not significantly different from each other $(P>0.01)$. Healthy control revealed significant differences in the ratio of neutrophils, lymphocytes and macrophages between the NS-LAD and S-LAD groups. There was no statistically significant difference in lymphocyte and macrophage levels between healthy control and NS-LAD groups. 
Table 2. ALP and LDH enzyme activities $(\mathrm{x} \pm \mathrm{Sx})$ in TW fluid from healthy control, NS-LAD and S-LAD groups.

\begin{tabular}{ccccc}
\hline \multirow{2}{*}{ Parameter } & $\begin{array}{c}\text { Healthy control } \\
(\mathrm{n}=12)\end{array}$ & $\begin{array}{c}\text { NS-LAD } \\
(\mathrm{n}=51)\end{array}$ & $\begin{array}{c}\text { S-LAD } \\
(\mathrm{n}=20)\end{array}$ & $P$ \\
\hline ALP $(\mathrm{U} / \mathrm{L})$ & $182.58 \pm 14.17 \mathrm{~b}$ & $2358.71 \pm 257.67 \mathrm{a}$ & $1461.25 \pm 200.50 \mathrm{a}$ & 0.001 \\
LDH (U/L) & $33.33 \pm 3.88 \mathrm{c}$ & $273.10 \pm 37.64 \mathrm{~b}$ & $1757.75 \pm 340.77 \mathrm{a}$ & 0.001 \\
\hline
\end{tabular}

$\mathrm{NS}-\mathrm{LAD}=$ Non Septic Lower Airway Disease; S-LAD= Septic Lower Airway Disease; a,b,c= Means that have the same letter on the same row are not significantly different from each other $(P>0.01)$. A statistically significant difference $(P<0.01)$ was found for mean ALP and LDH enzyme activities in TW fluid of all groups, except no statistically significant difference in ALP levels between NS-LAD and S-LAD groups.

Table 3. ALP and LDH enzyme activities $(x \pm S x)$ in blood serum from healthy control, non-septic inflammation and septic inflammation groups.

\begin{tabular}{ccccc}
\hline Parameter & $\begin{array}{c}\text { Healthy control } \\
(\mathrm{n}=12)\end{array}$ & $\begin{array}{c}\text { NS-LAD } \\
(\mathrm{n}=51)\end{array}$ & $\begin{array}{c}\text { S-LAD } \\
(\mathrm{n}=20)\end{array}$ & $P$ \\
\hline ALP $(\mathrm{U} / \mathrm{L})$ & $185.42 \pm 3.66$ & $191.41 \pm 1.69$ & $193.85 \pm 2.87$ & 0.175 \\
\hline LDH (U/L) & $284.42 \pm 4.20$ & $292.20 \pm 2.13$ & $296.15 \pm 4.49$ & 0.152 \\
\hline
\end{tabular}

NS-LAD $=$ Non Septic Lower Airway Disease; S-LAD $=$ Septic Lower Airway Disease. There was no statistically significant difference in blood serum enzyme activities between the groups.

\section{DISCUSSION}

In this cross-sectional study, ALP and LDH TW fluid activity was found to be significantly higher $(P<0.01)$ in both experimental groups compared to healthy control group, also between NS-LAD and SLAD groups as well. On the basis of these findings, it was suggested that ALP and LDH enzyme activites of TW fluid could be used as indicators of pulmonary inflammation and/or damage, and LDH enzyme activity is thought to be useful in differential diagnosis of racehorses with NS-LAD and S-LAD.

Respiratory tract disorders have been known to be one of the main causes of training disruption and interruption of racing competitions in racehorses. Particularly the lower airway diseases are the most frequently diagnosed conditions in sport horses evaluated for poor performance [22]. Diagnosis and discrimination of lower respiratory tract inflammation with septic and non-septic etiology usually consists of endoscopic examination, clinical signs, and cytological and bacteriological evaluation of BALF/TW samples. In addition, some researchers suggested that enzymatic changes of the BALF/TW samples reflect pathologic changes in the lower respiratory tract and could be used as a simple and rapid diagnostic tool in different animal species and humans as well. Maden et al. [19] determined that BALF LDH and ALP levels were significantly increased in 12 dogs with bronchopneumonia, but not in $8 \mathrm{dogs}$ with tracheobronchitis. According to the authors, ALP and LDH enzyme activities could be considered as pointers to pulmonary inflammation and/or damage. In another previous study ALP level in TW fluid of horses was found to be significantly different $(P<$ $0.05)$ between healthy control and asymptomatic lower respiratory tract inflammation groups [27]. Art et al. [1] claimed that myeloperoxidase activity was found to be significantly higher in BALFs of horses experimentally exposed to moldy hay and diagnosed as reccurent airway obstruction (RAO) than healthy control group. In humans, contamination of pleural effusions with bacterial agents resulted in increased number of neutrophils, pleural acidosis due to increased consumption of glucose and LDH increase $(1000 \mathrm{U} / \mathrm{L}<)$ due to neutrophil lysis [8]. In a previous study [5], measurement of ALP and LDH enzyme levels in BALF samples of humans with mainly polymorphnuclear neutrophils (group I) and with mainly alveolar macrophages (group II), revealed that LDH and ALP enzyme activities were higher in group I compared with group II. In the same study, no association was found between ALP activity and the cells present in BALF. The authors suggested that in contrast to LDH, ALP activity originated from cells not present in BAL fluid.

In the present study, ALP and LDH enzyme activities were determined in TW fluid of racehorses and mean ALP and LDH enzyme activities were found to be significantly higher in racehorses with 
both NS-LAD and S-LAD groups than healthy controls $(P<0.01)$. These results were in concordance with the previous studies performed in dogs [19], horses $[13,23]$ and humans $[5,8]$ mentioned above. In addition, LDH enzyme activity in the S-LAD group was determined to be higher $(P<0.01)$ than the NS-LAD group (Table 2). An increase in LDH activity could arise from different sources of cells including necrosis of airway epithelial cells, alveolar macrophages, or other pulmonary cell types. Local inflammatory cells such as alveolar macrophages and polymorphnuclear cells might had been a potential source of elevation in LDH concentration [5]. Especially in bacterial etiologies bacterial toxins causes degeneration and lysis of neutrophils and other cell types might have caused high LDH values as well [13]. In our study, based on cytology results were observed that increased levels of neutrophil $(\geq 80 \%)$, degenerative cell changes and presence of intracellular bacteria in the septic inflammation group. These results have supported the opinions $[6,8,9,17]$ association with increased LDH levels due to neutrophil lysis, cell damage and death. The increase of TW fluid ALP activity in horses with lower respiratory tract inflammation was reported that neutrophil immigration [11,27]. On the other hand, increase in ALP enzyme activity in bronchoalveolar lavage fluid in humans and rats has been shown as a marker of type II pneumocyte proliferation and pulmonary inflammation [2,11]. However, it is stated that ALP enzyme levels in neutrophils are low $(22 \mathrm{mIU} / \mathrm{mg}$ protein) compared to type II cells $(888 \mathrm{mIU} / \mathrm{mg}$ protein) and the main source of ALP is type II cells [11]. In addition, a decrease in BALF ALP enzyme activity has been reported in chronic IAD cases due to the decrease in type II cell function in horses [14]. In the light of these evaluations, in our study, high ALP enzyme activities in the experimental groups were interpreted as an indicator of type II cell damage along with neutrophil influx [2,11,14,27] and lower levels of ALP enzyme in S-LAD group than NS-LAD group may be explained as loss and/or damage of type II cell functions [14]. In addition, the fact that TW LDH enzyme activity was higher in the S-LAD group than the NS-LAD group due to it's role in bacterial etiology [13] was interpreted that this enzyme activity could be used in the differential diagnosis of septic and non-septic LAD cases.
The present cross-sectional study demonstrated that the majority of horses $(61.4 \%)$ with lower airway inflammation consisted of non-septic etiology. This result was expected by the authors because all of the horses those took part in the study are confined in stable boxes almost $20 \mathrm{~h}$ in a day. Respiration of hay dust, mould particles and fungal spores might have caused to non-septic inflammation and significant increase in TW fluid ALP enzyme activity.

During the study the authors also observed significant decrease in both mean ALP and LDH enzyme activities in TW fluids of horses after successful treatment in both non-septic and septic inflammatory conditions (Data were not shown). Especially clinically significant increase of LDH enzyme activity in septic conditions and ALP enzyme activity increase in non-septic inflammatory conditions and their significant decrease after successful treatment were encountered but more studies with high number of horses with different respiratory conditions should be performed in order to confirm the authors' observations.

\section{CONCLUSIONS}

Based on the present study's results it can be concluded that ALP and LDH enzyme activities in TW fluid could be considered as indicators to pulmonary inflammation and/or damage, and LDH enzyme activity is thought to be useful in distinguishing neutrophilic non-septic and septic pulmonary inflammation in racehorses with LAD. Although these results are promising, clinical and prognostic uses of these parameters warrant further research, especially in different inflammatory disorders.

\section{MANUFACTURERS}

${ }^{1}$ Jorgen Kruuse A.S. Langeskov, Denmark.

${ }^{2}$ Diasera A.S. Izmir, Turkey.

${ }^{3}$ BD-Becton Dickinson A.S. Sparks, NV, USA.

${ }^{4}$ Oxoid A.S. Basingstoke, United Kingdom.

${ }^{5}$ Siemens Healtineers A.S. Istanbul, Turkey. ${ }^{6}$ GBL-Gul Biyoloji A.S. Istanbul, Turkey.

Ethical approval. For the present study ethical approval was obtained from the Ethical Committee, Faculty of Veterinary Medicine, University of Selcuk (Number 2006-2006/079).

Declaration of interest. The authors report no conflict of interest. The authors alone are responsible for the content and writing of paper. 


\section{REFERENCES}

1 Art T., Franck T., Lekeux P., Moffarts B., Couetil L., Becker M., Kohnen S., Dupont G.D. \& Serteyn D. 2017. Myeloperoxidase concentration in bronchoalveolar lavage fluid from healthy horses and those with recurrent airway obstruction. The Canadian Journal of Veterinary Research. 70: 291-296.

2 Capelli A., Lusuardi M., Cerutti C.G. \& Donner C.F. 1997. Lung alkaline phosphatase as a marker of fibrosis in chronic interstitial disorders. American Journal of Respiratory Critical Care Medicine. 155: 249-253.

3 Carvallo F.R., Francisco A.U., Santiago S.D., Hill A.E. \& Arthur R.M. 2017. Retrospective study of fatal pneumonia in rachorses. Journal of Veterinary Diagnostic Investigation. 29(4): 450-456.

4 Cian F., Monti P. \& Durham A. 2015. Cytology of the lower respiratory tract in horses: An updated review. Equine Veterinary Education. 27: 544-553.

5 Cobben N.A.M., Drent M., Jacobs J.A., Schmitz M.P.J., Mulder P.G.H., Henderson R.F., Wouters E.F.M. \& van Dieijen-Visser M.P. 1999. Relationship between enzymatic markers of pulmonary cell damage and cellular profile: a study in bronchoalveolar lavage fluid. Experimental Lung Research. 25: 99-111.

6 Colagiovanni D.B., Meyer D.J. \& Wolf J.M. 2005. Increased serum alkaline phosphatase activity originating from neutrophilic leukocytes. Clinical Chemistry. 9: 51.

7 Cowell R.L. \& Tyler R.D. 2002. Diagnostic Cytology and Hematology of the Horse. 2nd edn. St. Louis: C.V. Mosby Company, pp.73-85.

8 Çuhadaroğlu S., Özgül M.A. \& Demir A. 2012. Plevral efüzyonlarda fibrinolotik tedavi. Turk Thoracic Journal. 49: 40-44.

9 Fossa S.D., Poulsen J.P. \& Aaserud A. 1992. Alkaline phosphatase and lactate dehydrogenase changes during leucocytosis induced by G-CSF in testicular cancer. The Lancet. 340: 1544.

10 Gerber V., Straub R., Marti E., Hauptman J., Herholz C., King M., Imhof A., Tahon L. \& Robinson NE. 2004. Endoscopic scoring of mucus quantity and quality: observer and horse variance and relationship to inflammation, mucus viscoelasticity and volume. Equine Veterinary Journal. 36: 576-582.

11 Henderson R.F., Scott G.G. \& Waide J.J. 1995. Source of alkaline phosphatase activity in epithelial lining fluid of normal and injured F344 rat lungs. Toxicology and Applied Pharmacology. 134: 170-174.

12 Hoffman A. 2008. Bronchoalveolar Lavage: Sampling Technique and Guidelines for Cytologic Preparation and Interpretation. Veterinary Clinics of North America: Equine Practice. 24: 423-435.

13 Jocelyn N.A., Wylie C.E., Lean M., Barrelet A. \& Foote A.K. 2018. Association of neutrophil morphology with bacterial isolates in equine tracheal wash samples. Equine Veterinary Journal. 50(6): 752-758. doi: 10.1111/evj.12837

14 Jorge M.L.L.A., Viscardi V., Silva K.M., Otaka J.N.P., Alencar N.X., Torres R.D. \& Lessa D.A.B. 2014. Alkaline phosphatase activity in bronchoalveolar lavage of police horses in Rio de Janeiro State, Brazil. Ciência Rural. 44: 92-96.

15 Kalina M., Levi D. \& Riklis S. 1990. Modulation of alkaline phosphatase activity in alveolar type II like cells. Journal of Histochemistry and Cytochemistry. 95: 97-103.

16 Kennerman E., Gocmen H., Cihan H. \& Ulgen U. 2018. Results of cytological and microbiological examination using tracheal aspiration in racehorses with lower respiratory tract disease. Acta Veterinaria Brno. 87: 339-345.

17 Kubota M. \& Haruta T. 2007. Neutrophil alkaline phosphatase activity in respiratory viral infection. Journal of Infection and Chemotherapy. 12(6): 387-390.

18 Laus F., Attili A.R., Cerquetella M., Spaterna A., Tesei B. \& Cuteri V. 2009. Endoscopic findings, microbiological and cytological evaluation of tracheal aspirates in a population of standardbred horses with poor performances. Veterinarni Medicina. 9: 444-450.

19 Maden M., Altunok V., Birdane, F.M., Aslan V. \& Nizamlığlu M. 2001. Specific enyzme activities in bronchoalveolar lavage fluid as an aid to diagnosis of tracheobronchitis and bronchopneumonia in dogs. Research in Veterinary Science. 71: 141-145.

20 Malikides N., Hughes K.J., Hodgson D.R. \& Hodgson J.L. 2003. Comparison of tracheal aspirates and bronchoalveolar lavage in racehorses 2. Evaluation of the diagnostic significance of neutrophil percentage. Australian Veterinary Journal. 81(11): 685-687.

21 Rossi H., Virtala A.M., Raekallio M., Rahkonen E., Rajamaiki M.M. \& Mykkanen A. 2018. Comparison of tracheal wash and bronchoalveolar lavage cytology in 154 horses with and without respiratory signs in a refferal hospital over 2009-2015. Frontiers in Veterinary Science. 5: 61. 
22 Saulez M.N., Cebra C.K. \& Tornquist S.J. 2004. The Diagnostic and Prognostic Value of Alkaline Phosphatase Activity in Serum and Peritoneal Fluid from Horses with Acute Colic. Journal of Veterinary Internal Medicine. 18: 564-567.

23 Sharma A.K., Randhawa C.S., Narang A., Sood N.K. \& Rai T.S. 2017. Cytological and bacteriological evaluation of tracheal aspirates fort he diagnosis of lung affections in horses. Journal of Animal Research. 7: 459-464.

24 SPSS. 2020. IBM SPSS Statistics V22.0.0, Licensed to Selcuk University.

25 Thornton J.R. \& Lohni M.D. 1992. Tissue and Plasma Activity of Lactic Dehydrogenase and Creatine Kinase in the Horse. Equine Veterinary Journal. 4: 235-238.

26 Trueman K.F., Lumsden J.H. \& McSherry B. 1983. Examination of the Origin of Increased Equine Serum Alkaline Phosphatase Concentrations. Canadian Veterinary Journal. 24: 108-111.

27 Viscardi V., Jorge M.L.L.A., Silva K.M., Sad E.P. \& Fonseca A.B.M. 2016. Alkaline phosphatase activity in airway fluid obtained by tracheal wash from adult horses. Veterinary Clinical Pathology. 45(2): 376-80. doi: 10.1111/vcp.12360. 